Abstracta Iranica

Revue bibliographique pour le domaine irano-aryen

Volume 34-35-36 | 2017

Comptes rendus des publications de 2011-2013

\title{
D. Grassian. Iranian and diasporic literature in the 21st century: a critical study
}

\section{Laetitia Nanquette}

\section{OpenEdition}

10 Journals

\section{Édition électronique}

URL : http://journals.openedition.org/abstractairanica/41369

DOI : 10.4000/abstractairanica.41369

ISSN : 1961-960X

Éditeur :

CNRS (UMR 7528 Mondes iraniens et indiens), Éditions de l'IFRI

Référence électronique

Laetitia Nanquette, "D. Grassian. Iranian and diasporic literature in the 21 st century: a critical study », Abstracta Iranica [En ligne], Volume 34-35-36 | 2017, document 1, mis en ligne le 15 juillet 2016, consulté le 28 septembre 2020. URL : http://journals.openedition.org/abstractairanica/41369; DOI : https://doi.org/10.4000/abstractairanica.41369

Ce document a été généré automatiquement le 28 septembre 2020.

Tous droits réservés 


\title{
D. Grassian. Iranian and diasporic literature in the 21st century: a critical study
}

\author{
Laetitia Nanquette
}

\section{RÉFÉRENCE}

D. Grassian, Iranian and diasporic literature in the 21st century: a critical study. Jefferson, North Carolina, McFarland, 2013, 280 p.

1 Cet ouvrage se veut un aperçu de la littérature iranienne contemporaine de la diaspora, insistant sur les auteurs qui s'opposent aux polarisations qui voudraient faire de la littérature le bastion de la résistance à l'Etat islamique ou au contraire son auxiliaire.

2 Grassian s'intéresse aux écrivains nés après 1960 et plus particulièrement à ceux nés dans les années 80, appelés aux Etats-Unis la génération $\mathrm{X}$, et en Iran la " génération brûlée ».

3 La plupart des chapitres s'intéressent aux écrivains féminins de mémoires, comme Marjane Satrapi, Dalia Sofer, Porochista Khakpour, Azar [Ādar] Nafīsī, Āzāde Mo'āvenī et Firoozeh [Fīrūze] Dumas.

4 Cet ouvrage comporte également un chapitre sur Šahryār Mandanīpūr, un sur les blogs, un sur les mémoires de prison et un sur la poésie contemporaine de la diaspora.

5 Bien qu'il soit généreux dans son désir de montrer la contribution positive de la littérature de la diaspora aux dialogues des civilisations, cet ouvrage ne contient pas d'idées nouvelles par rapport au large corpus de textes théoriques sur les mémoires des iraniens-américains ni même sur les blogs. Il n'y a pas non de réflexion théorique sur le genre ou sur l'identité pour le démarquer des études précédentes. 


\section{AUTEURS}

\section{LAETITIA NANQUETTE}

University of New South Wales, Sydney 